\title{
Ultrastructure of Mycoplasma orale Serotype 1 in Agar Growth
}

\author{
By M. NAKAMURA AND M. KAWAGUCHI \\ Department of Microbiology, Kurume University School of Medicine, Kurume, Japan
}

(Accepted for publication II November 197I)

\begin{abstract}
SUMMARY
Vertical ultrathin sections of a colony of Mycoplasma orale serotype I, N-I strain, which had been isolated from a patient with leukaemia, have been examined by electron microscopy.

In the micrographs, the ultrastructural appearance of Mycoplasma orale in agar growth could be divided into two patterns. One was a mycelial growth form which was observed in the surface area and resembled growth in broth. The other was a pattern of binary fission observed in the deep area of the agar. These growth features differ from those of human mycoplasmas previously reported.
\end{abstract}

\section{INTRODUCTION}

Recently, ultrastructures of mycoplasmas have been described by use of newly developed techniques of electron microscopy. Fine structures of Mycoplasma orale and a possible growth cycle suggested by their findings were described by Anderson \& Barile (1966) and Furness (1970). Anderson \& Barile (1966) reported that $M$. orale grown in broth culture showed a long filamentous form; the filaments were 50 to $100 \mathrm{~nm}$ wide and up to several $\mu \mathrm{m}$ long and were sometimes branched. Furness ( 1970 ) reported that $M$. orale serotype 2 divided by binary fission with a mean generation time of $3 \mathrm{~h} \pm 25 \mathrm{~min}$ in a synchronized culture.

The present paper describes ultrathin micrographs of agar growth of Mycoplasma orale serotype I, N-I strain, taken by the section method of Domermuth, Nielsen, Freundt \& Birch-Anderson (1964) and Knudson \& MacLeod (1970). The N-I strain of M. orale serotype I was directly isolated from a patient with leukaemia by Hayflick \& Koprowski (I956) and differed from other strains of $M$. orale by its failure to show growth inhibition by antiserum.

\section{METHODS}

Mycoplasma orale serotype I. The N-I strain of $M$. orale serotype I was kindly supplied by Dr Hayflick in 1966, and maintained in PPLO agar and broth in our laboratory.

Culture. To obtain colonies of Mycoplasma orale for electron microscopy, a culture in PPLO broth was inoculated on to PPLO agar and incubated for 5 days at $37^{\circ}$ under aerobic conditions. The PPLO agar consisted of $70 \%$ (v/v) PPLO agar (Difco), $20 \%$ (v/v) horse serum, $10 \%(\mathrm{v} / \mathrm{v})$ freshly prepared $25 \%$ yeast extract, and $\mathrm{I} \%(\mathrm{w} / \mathrm{v})$ thallium acetate and penicillin (to give I0,000 units of penicillin $/ \mathrm{ml}$ medium).

Ultrathin section preparation. Mycoplasma colonies growing on agar were fixed in situ, and embedded for sectioning by the Knudson \& MacLeod (I970) method, as follows. Glutaraldehyde, $2.5 \%(\mathrm{v} / \mathrm{v})$ in $0.1 \mathrm{M}$-phosphate buffer $(\mathrm{pH} 7 \cdot 2)$, was gently introduced over the agar surface at room temperature. The agar plate was immediately placed in ice for $50 \mathrm{~min}$. Each colony was located microscopically, and a cylindrical plug of agar excised by use of a modified capillary pipette. The agar plug was fixed in $2.5 \%$ glutaraldehyde at $0^{\circ}$ for 


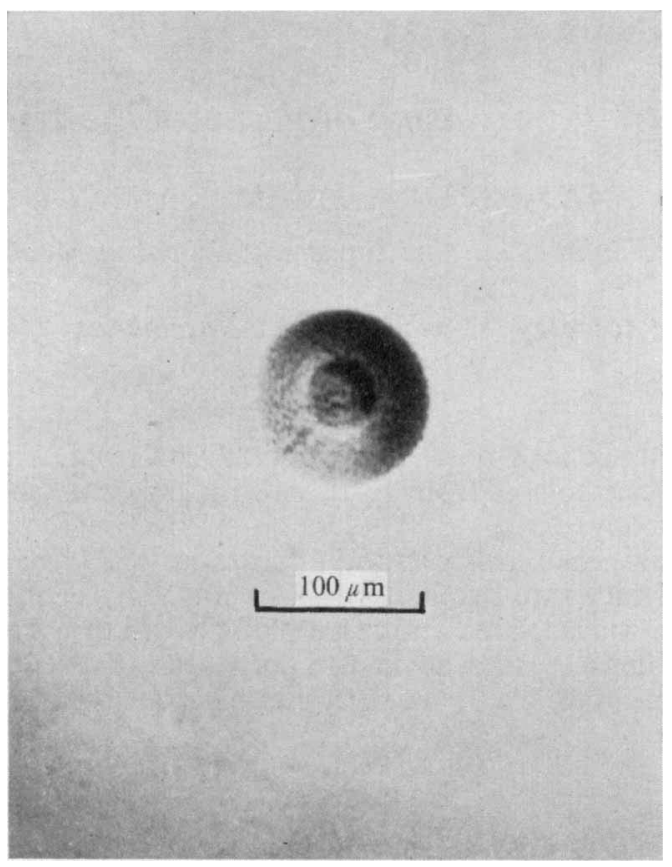

Fig. I. A colony of Mycoplasma orale on PPLO after 5 days of incubation at $37^{\circ}$ under aerobic conditions.

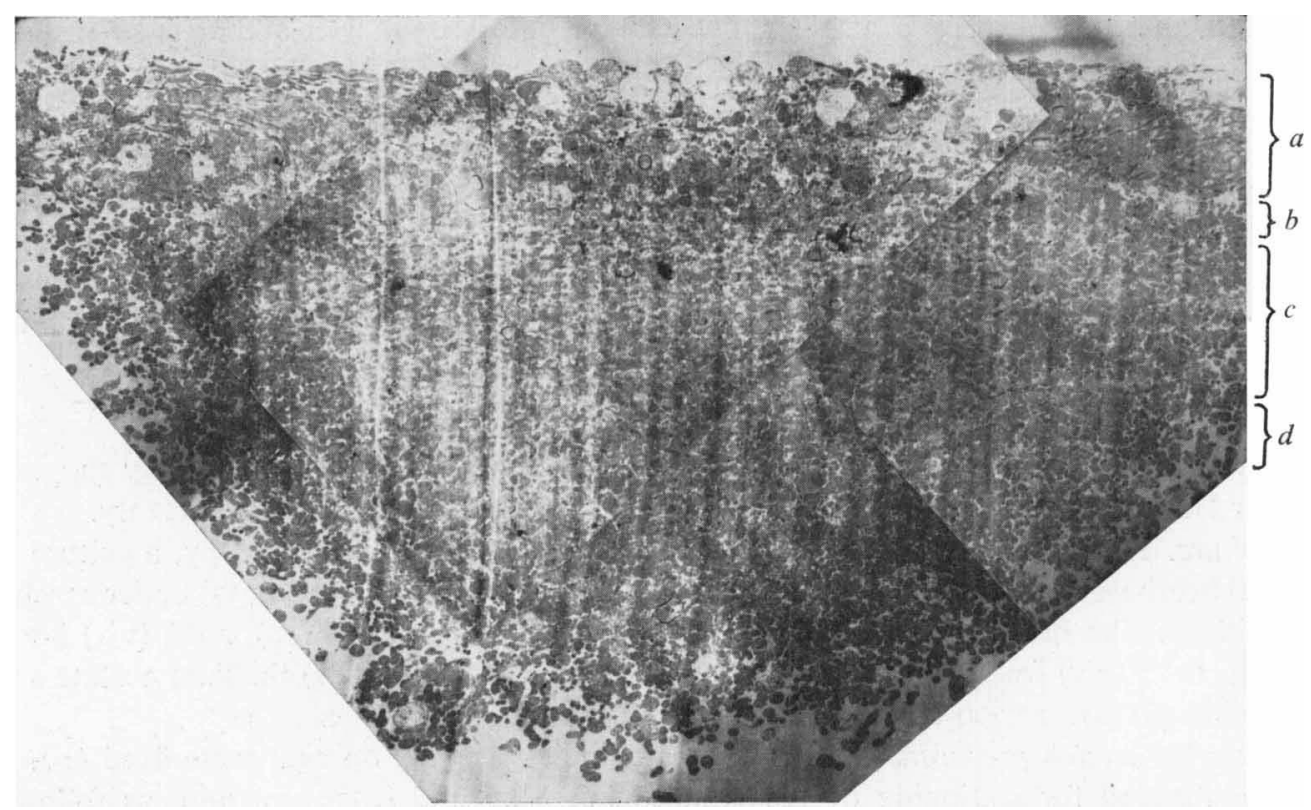

Fig. 2. Electron micrograph of longitudinal section of a colony of Mycoplasma orale grown in agar: $(a)$ the surface; $(b)$ a less-populated area; $(c)$ a cell-crowded area; and $(d)$ a lower diffuse front. 

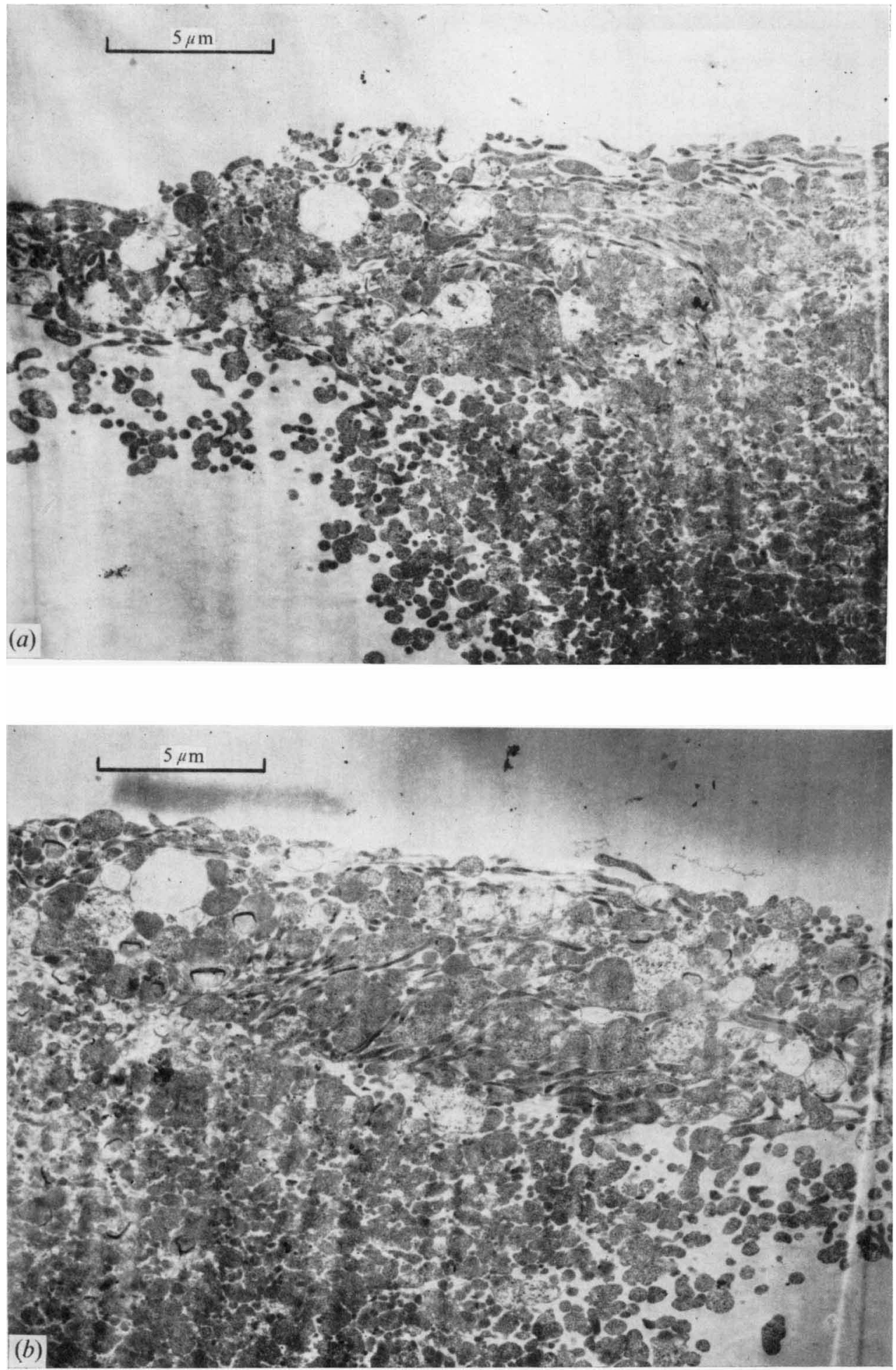

Fig. $3 a$ and $b$. The periphery of the surface; each side of a section through a colony (magnified from Fig. 2) showing both less-populated and cell-crowded areas. 

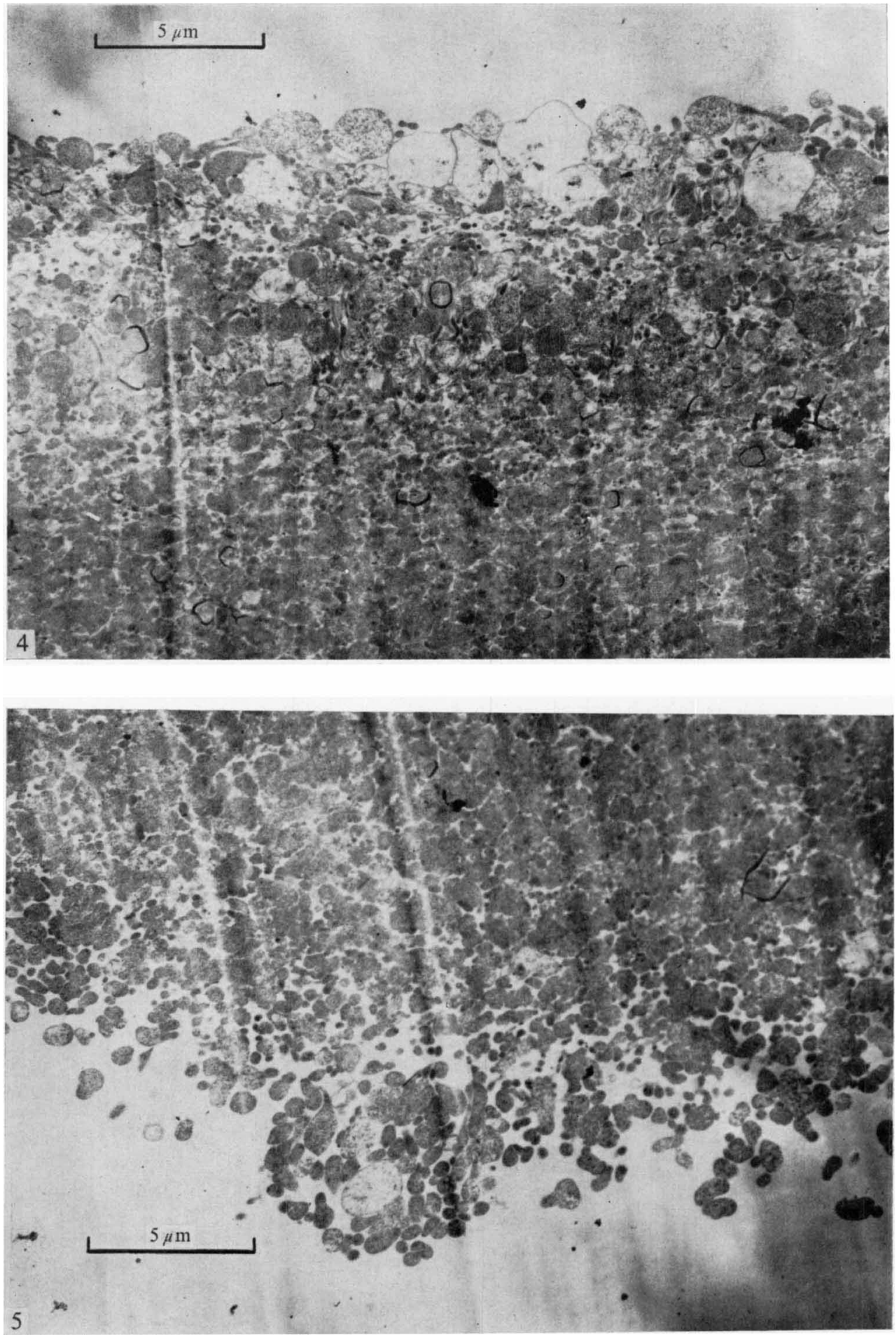

Fig. 4. The central part of the surface of a colony.

Fig. 5. The lower diffuse front of the colony below the agar surface. 


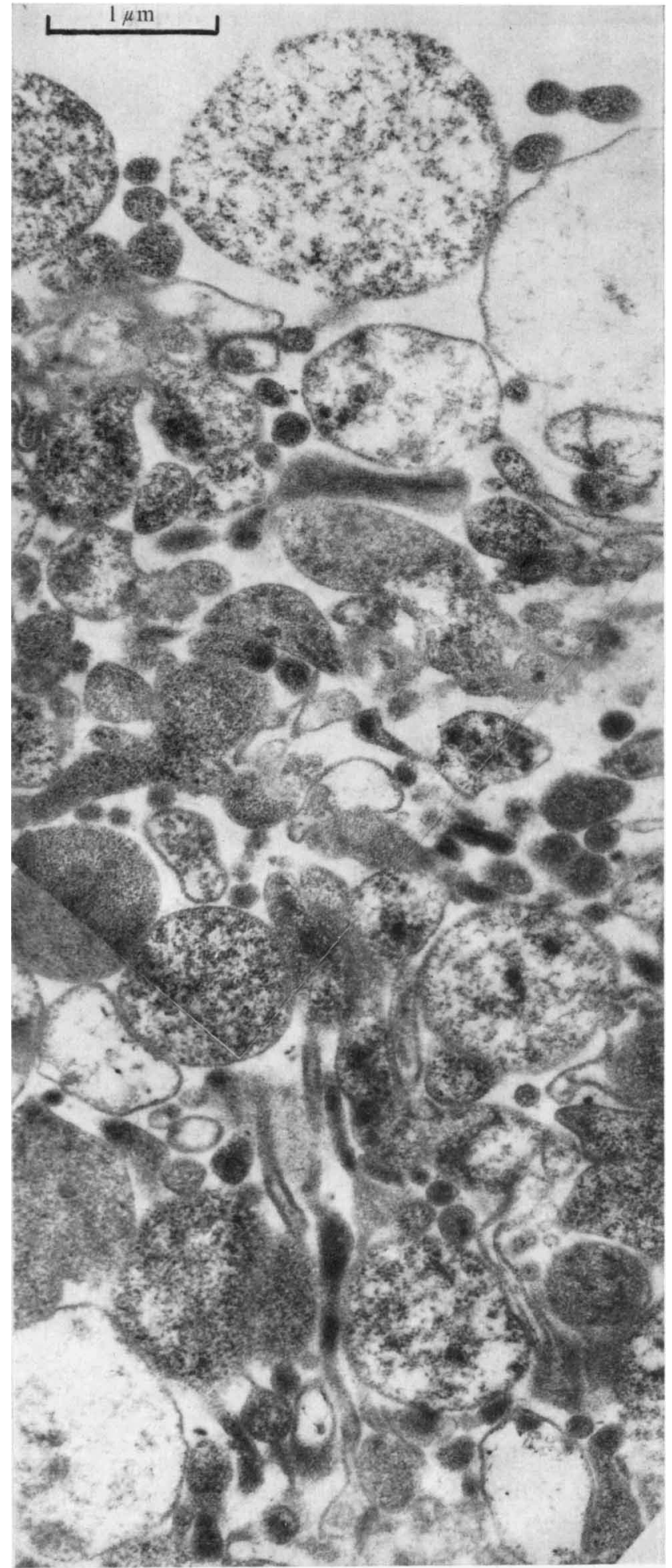

Fig. 6. Highly magnified electron micrograph of a central part of the surface of a colony. 


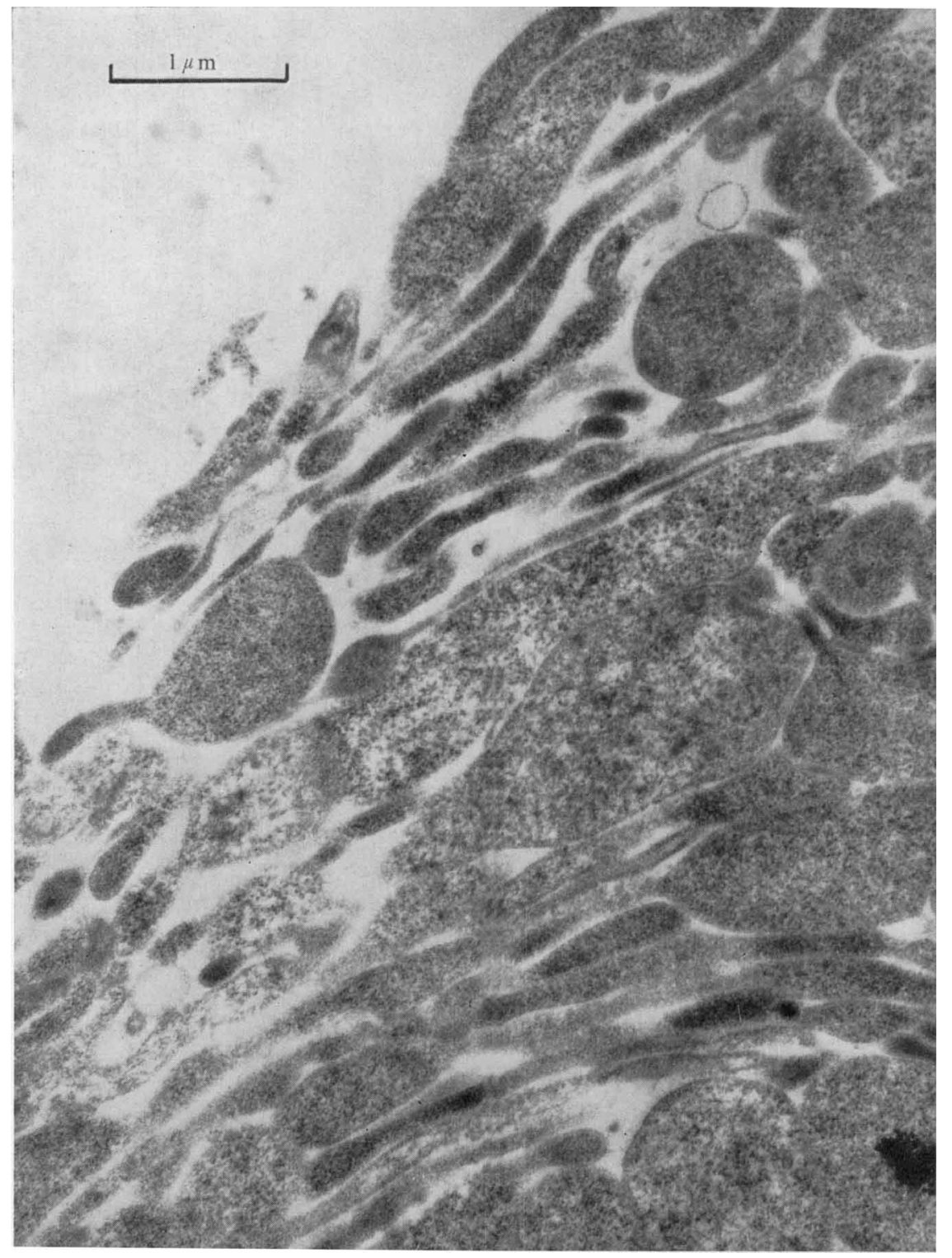

Fig. 7. Highly magnified electron micrograph of a peripheral part of the surface of a colony.

an additional $30 \mathrm{~min}$, to ensure complete diffusion of the fixative into the agar. The plug was then rinsed in water and immersed in $2 \%(\mathrm{~W} / \mathrm{v})$ osmium tetroxide in $0 . \mathrm{I} \mathrm{M}$-phosphate buffer, $\mathrm{pH} 7 \cdot 2$ for $\mathrm{I} h$ at $0^{\circ}$. Following a brief rinse with water, the fixed plug was rapidly dehydrated through a graded series of acetone and flat-embedded in epoxy resin by a modification of the method of Luft (196I). Colonies were clearly visible in the epoxy resin when viewed under a dissecting microscope. This facilitated trimming of the block for thin-sectioning. It was ensured that the block orientation was such that the sections were longitudinal through a colony. The block was sectioned by use of a Porter-Blum ultramicrotome. Silver to gold sections (60 to $150 \mathrm{~nm}$ thick) were placed on uncoated I50-mesh copper grids. Contrast was 


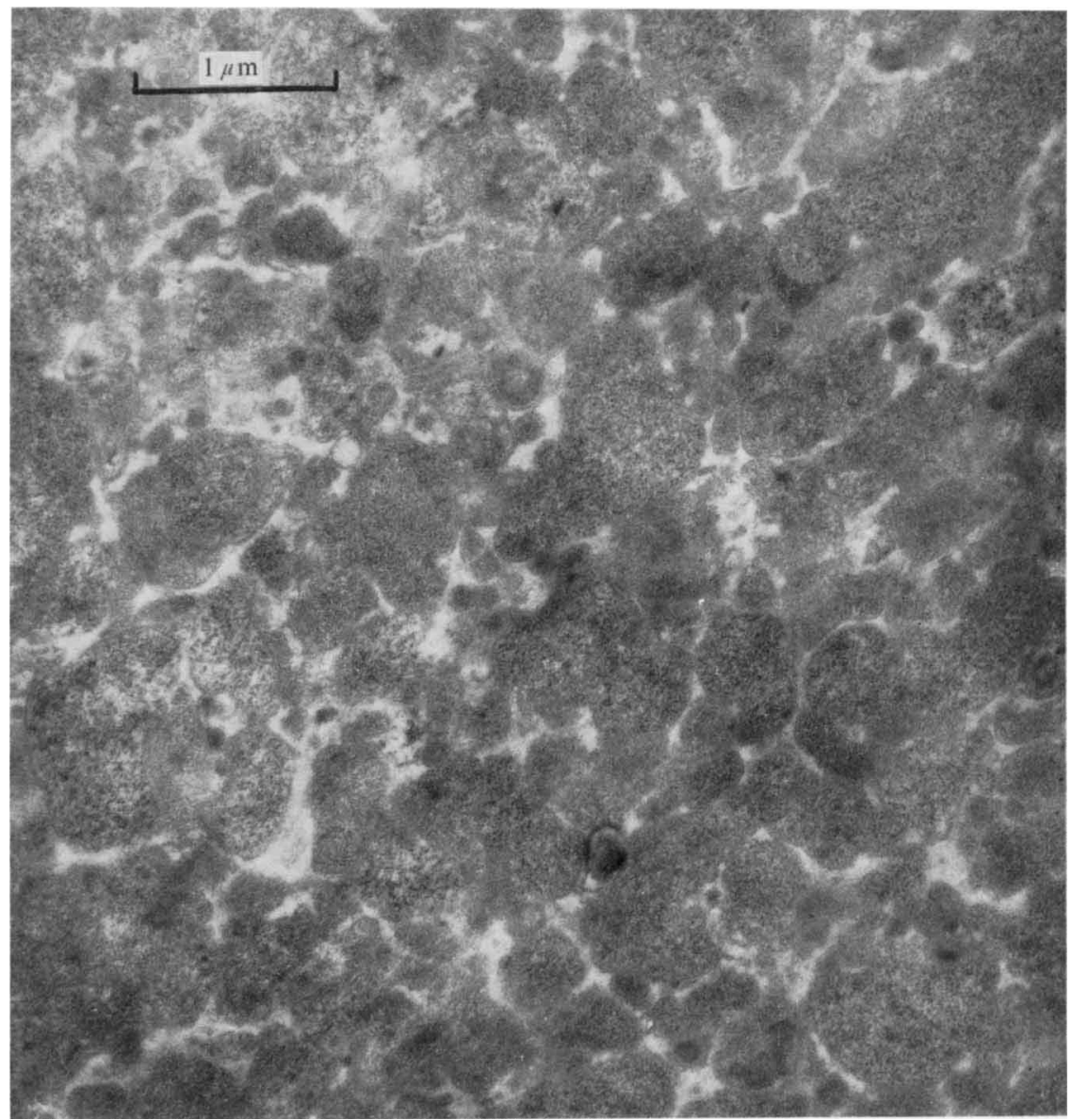

Fig. 8. Highly magnified electron micrograph of the cell-crowded area of a colony.

enhanced with uranyl acetate followed by treatment with Reynolds's lead citrate for to min (Reynolds, I963). The grids were examined by a Nihon-Denshi JEM-7 electron microscope.

\section{RESULTS}

Whole view of colony. A colony of Mycoplasma orale serotype I grown on PPLO agar is illustrated in Fig. I. The colony produced after aerobic cultivation for 5 days at $37^{\circ}$ is round, usually 30 to $100 \mu \mathrm{m}$, with a nipple $\mathrm{I} 5$ to $36 \mu \mathrm{m}$ in diameter.

In ultrathin section of the colony (Fig. 2), the longitudinal section may be divided into four layers; the surface $(a)$, a less populated area $(b)$, a cell-crowded area $(c)$, and a lower diffuse front $(d)$. This resembles the findings of Knudson \& MacLeod (I970) for Mycoplasma salivarium, although the less populated area of the Mycoplasma orale colony is markedly thinner. Furthermore, the absence of a less-populated area in the central part of the subsurface is a unique feature of $M$. orale.

Fine structure of mycoplasma cells located at each layer. The surface area. This is shown in section at the periphery (Fig. 3a,b) and centre (Fig. 4) of the upper surface and at the edge of the lower diffuse front (Fig. 5). The notable features of the surface are: (i) there are various 


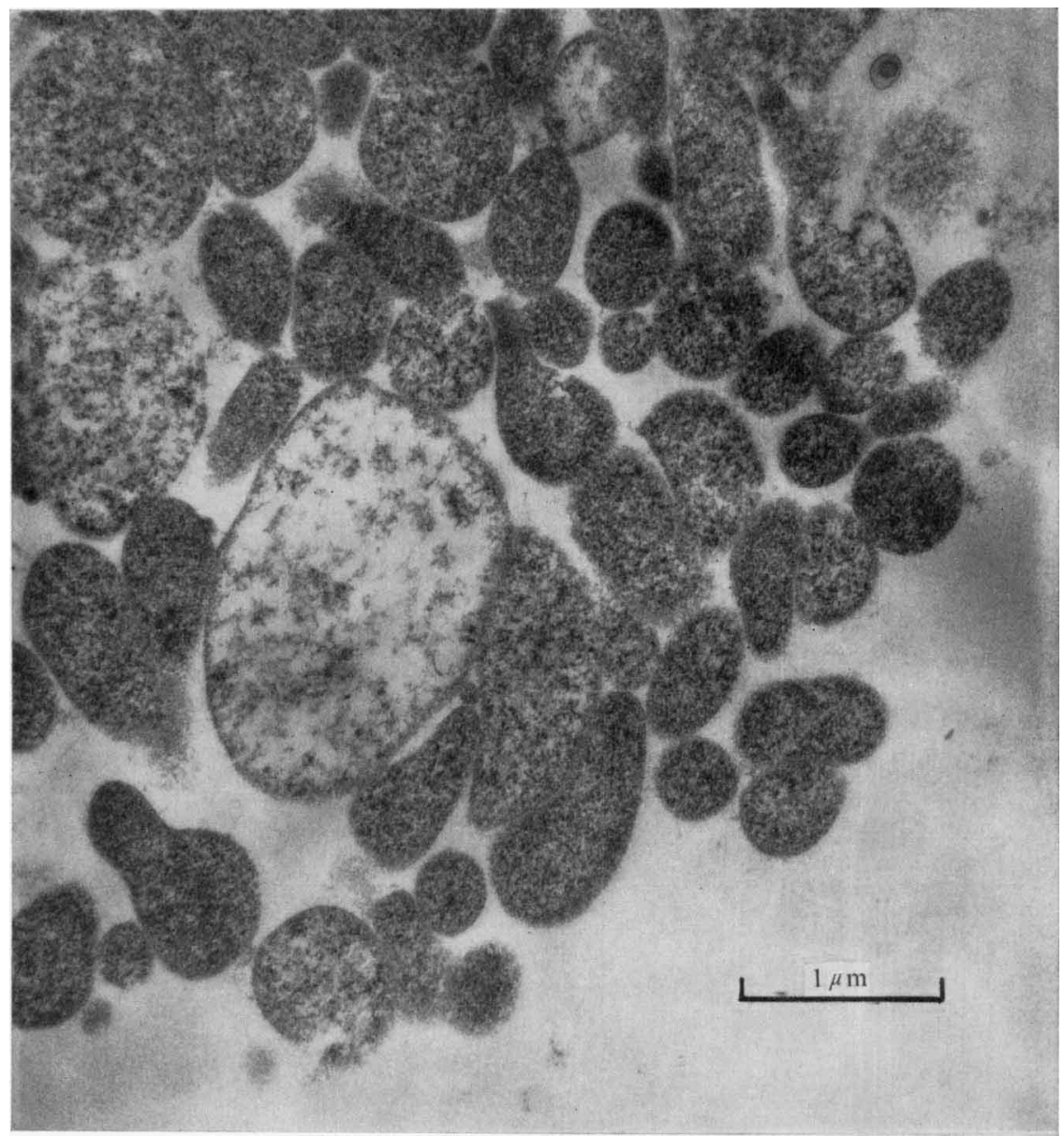

Fig. 9. Highly magnified electron micrograph of the lower diffuse front of the colony below the agar surface.

sizes and kinds of cells; (ii) the centre part of the surface differs from the peripheral parts in having no less-populated layer; (iii) a large number of small electron dense bodies are visible in the centre part; and (iv) filamentous cells are observed only in the surface - they are arranged vertically in the centre part and diagonally, from periphery to the centre, in the peripheral part.

Highly magnified electron micrographs of fine structures of cells located in the central and peripheral parts of the surface are illustrated in Fig. 6 and 7. In Fig. 6, central part, there are many kinds of cells: a very large empty body ( $\mathrm{I} \cdot 8$ to $2.3 \mu \mathrm{m})$, presumably not viable; a large cell $(\mathrm{I} \cdot 6$ to $\mathrm{I} \cdot 9 \mu \mathrm{m})$ containing ribosome-like granules and DNA-like substances; small electron dense bodies $(67$ to $100 \mathrm{~nm}$ ), presumably elementary bodies, and some filamentous forms arranged vertically. In Fig. 7 there are many long filamentous cells $(2 \cdot 7 \mu \mathrm{m} \times 45 \mathrm{~nm})$ which are arranged diagonally and contain electron dense particles and a small round swelling $(220 \mathrm{~nm})$ at the end of the filament, large bodies containing ribosome-like substance and budding forms.

Less-populated area. The less-populated area divides the colony into two parts, the surface 


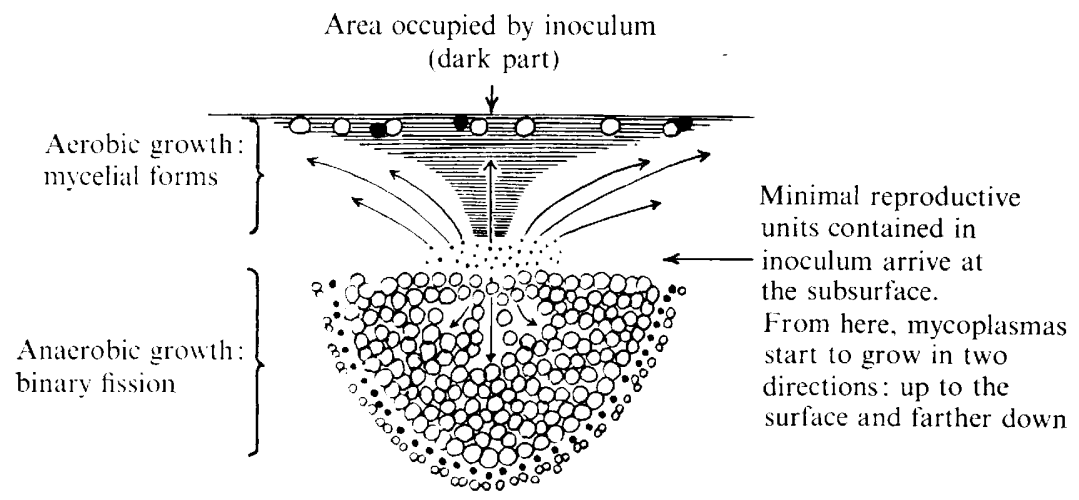

Fig. 10. A possible scheme for the growth of Mycoplasma orale on agar.

and the cell-crowded area (Fig. $3 a, b$ ). There are no characteristic cells in this area at the edge of colony. However, there are many elementary bodies in the centre part which correspond to the cell-crowded area, as shown in Fig. 4 and 6.

Cell-crowded area. A large number of less dense, indefinite structure cells of various sizes are crowded into this area; most of the cells present appear to contain ribosome-like granules (Fig. 8).

Lower diffuse front. Many small electron dense bodies, which are larger than elementary bodies, can be seen at the edge; large bodies containing ribosomes and paired cells, presumably arising during binary fission, are also present (Fig. 9).

\section{DISCUSSION}

As shown by Domermuth et al. (1964), the proportion of small to large cells varies in different parts of a mycoplasma colony seen in vertical section through colonies on solid medium. Very large empty cells predominate in the superficial area, while the small, dense, and medium-sized cells are most numerous further down in the medium. These results were also obtained in our work; however, additional cell features were noticed. First, cell morphology of agar growth of Mycoplasma orale is divided into two patterns by the line of the less-populated area seen in section; filamentous cells were observed in the surface and small or large round cells were seen in the lower part of the colony, where filamentous cells were never seen. Secondly, the filamentous forms were arranged vertically in the centre part and diagonally in the peripheral part of the colony, with the focal point of the central region at the upper edge of the cell-crowded area. On the basis of these findings, the following scheme for the agar growth of $M$. orale can be speculated (Fig. 10). When broth cultures containing mycoplasmas of various ages are inoculated on to the surface of PPLO agar, a part of the inoculum drops to the subsurface area leaving a majority of organisms on the surface. This is because PPLO agar is semisolid. Minimal reproductive units which arrive at the appropriate region for replication may start to grow from there. At limiting conditions of oxygen tension, mycoplasmas may grow aerobically toward the surface as a mycelial form, and anaerobically further down by binary fission. Therefore, the region of the agar surface for developing mycoplasmas may be considered similar to that in broth, because long filamentous forms were observed by Kim, Clyde \& Denny (1966) in broth culture. Presumably, the various sizes and large empty bodies present in the surface area represent the 
remaining inoculum. It is also possible that the less-populated area of the colony would be a place where minimal reproductive units contained in the inoculum gathered and could, therefore, perhaps be a starting place for replication. A light microscope observation of colony formation of $M$. orale on PPLO agar indicated that a nipple was initially produced after 4 days' cultivation at $37^{\circ}$, and then the periphery was gradually formed (M. Nakamura \& M. Kawaguchi, unpublished observations).

From the data obtained here, it is strongly suggested that the replication mode of mycoplasmas is changeable, depending upon the culture conditions.

It is not yet clear whether other Mycoplasma orale strains develop in the same pattern in PPLO agar as obtained here with the N-I strain of $M$. orale serotype $I$.

This investigation was aided by Grant (no. A-7014) from the Ministry of Education of Japan I97I.

\section{REFERENCES}

ANDERSON, D. R. \& BARILE, M. F. (1966). Ultrastructure of Mycoplasma orale isolated from patients with leukaemia. Journal of the National Cancer Institute 36, I6I-167.

Domermuth, C. H., Nielsen, M. H., Freundt, E. A. \& Birch-Anderson, A. (1964). Ultrastructure of Mycoplasma species. Journal of Bacteriology 88, 727-744.

FurNESS, G. (1970). The growth and morphology of mycoplasmas replicating in synchrony. Journal of Infectious Diseases 122, I46-I 57.

HAYFLICK, L. \& KoprowsKi, H. (1956). Direct agar isolation of Mycoplasma from human leukemic bone marrow. Nature, London 205, 7I3-7I4.

Kim, K. S., ClyDE, W. A. Jun., \& DenNY, F. W. (1966). Physical properties of human Mycoplasma species. Journal of Bacteriology 92, 2I 4-2 I 9.

KNUdSON, D. S. \& MACLeOD, R. (1970). Mycoplasma pneumoniae and Mycoplasma salivarium: electron microscopy of colony growth in agar. Journal of Bacteriology ror, 609-61 7 .

LuFT, H. H. (196I). Improvements in epoxy resin embedding methods. Journal of Biophysical and Biochemical Cytology 9, 409-414.

REYNOLDS, E. S. (1963). The use of lead citrate at high $\mathrm{pH}$ as an electron-opaque stain in electron microscopy. Journal of Cell Biology 17, 208-212. 